\title{
Gamification of Professional Development for First Year Engineering Students
}

\author{
Jason Bazylak \\ University of Toronto \\ jbazylak@mie.utoronto.ca
}

\begin{abstract}
Approximately 1.23 billion people play video games. Gamification is the study of what motivates gamers to invest thousands of hours into these games, and more importantly attempts to derive principles of gamification that can be applied to motivate people to participate in non-video game tasks with equal zeal. Education is one area where gamification is being explored.

One gamification principle is to give participants a clear indication of their progress. In video games this is often depicted as 'points'. The typical grade system could be interpreted as a type of point system, but one without much flexibility. Implementation of a bonus point system as an overlay to the standard grade system may allow for more flexibility.

In this study this gamification principle was used to motivate students in a first year design course to participate in optional professional development activities and to foster an active online peer feedback and instruction community. With relatively minor modifications and repackaging of an existing evaluation methods students were motivated to give optional oral presentations, attend optional skill development workshops, and to contribute extensively to an online learning community.

This implementation of gamification was found to have a net positive effect on student participation in Professional Development activities. Where it succeeded and where it failed will be explored.
\end{abstract}

Keywords: Gamification, professionalism, motivation, first year engineering.

\section{BACKGROUND ON GAMERS AND GAMING}

Games, of all kinds but most specifically video games, have had a place in my heart since I was a child. My first video gaming experience outside of an arcade, to which I was not supposed to frequent by parental decree, was in the classroom in the mid 1980's. I remember racing through my math assignment in order to earn the privilege of 15 minutes on the classroom computer (an Apple IIe I think) to play Oregon Trail [1]. I would strategize my way around broken wagon wheels, dysentery, and the recess bell which was my signal to "turn off that machine," in order to cross America in the 1800 's. It was a positive learning experience for me, both motivating me to do my math assignments and to learn a little about history. Unfortunately it was a rare experience due to splitting one computer between an entire classroom. It got slightly better when my elementary school purchased a whole computer lab and my geography skills were challenged by Where in the World is Carmen Sandiego? [2].

The value of Oregon Trail and other edu-games in the classroom was widely explored even back then and for many of us who grew up during that time these games are an indelible memory. What is less commonly known is that pioneers (of the computer scientist type, not the Oregon Trail type) such as Bowman were already exploring the psychology of what motivated video game players like me to attack my math assignment with such zeal in order to hunt monochrome animals using a four arrow keyboard.

Bowman studied the "addictiveness" of the Pac-Man arcade game and concluded that was due to:

“...an action system where skills and challenges are progressively balanced, goals are clear, feedback is immediate and unambiguous, and relevant stimuli can be differentiated from irrelevant stimuli." (p. 15) [3].

Fast forward 25+ years and video games have developed into the dominate entertainment media industry. Globally in 20131.23 billion people are gamers and will spend over $\$ 70$ billion on their games [4]. Compare this to the $\$ 15$ billion revenue generated by the entire global recorded music industry in 2013 [5]. The rise of the casual gamer brought on by the expansion of 
Facebook and mobile games, means that gamers are no longer a niche demographic. Gaming is reaching more and more people with my 72 year old mother bordering on addicted to her Facebook games and Canada being the first country in the world to have more female mobile gamers than male [6].

The more recently the term gamification has come into usage. Pre-2004 there was no term gamification, but by 2010 it was a common term in business, marketing, and education. Its meteoric rise has led to some disagreement on the definition of the term, but a generally definitions revolve around:

Gamification: use of motivational factors that drive people to play games to motivate people to do nongaming tasks.

However as with any trendy term it is being used in other ways. As Landers points out in the education world when someone says,

I would like to "gamify" my course, they might be thinking:

1) I'd like to add some games to my course.

2) I'd like to teach my students using games.

3) I'd like to make assignments more fun.

4) I'd like to motivate my students to do more work. [7]

The edu-games discussed earlier were an implementation of items 1) and 2) and are not a new development. However more recent definitions of gamification focus on 3) and 4). At this level it is not about actual games, but rather the psychological understanding of what motivates people to game and can we transfer this understanding to manipulate people into doing what you want them to do.

Modern day gamification pioneers like Tom Chatfield have focused on these transferable motivational factors. He has identified seven of them.

1) Experience bars measure progress

2) Multiple short and long term goals

3) Rewards for efforts

4) Rapid, frequent and clear feedback

5) Element of uncertainty

6) Windows of enhanced engagement

7) Other people [8]

In an extensive literature review on gamification Hamari et al. concluded that generally gamification was found to have positive effects, but the degree of those positive effects depends on both the context and the characteristics of the users. For instance he found that education was the most common context, at least in peer reviewed literature, and also had the most positive effects when used to motivate students. He does qualify this with the fact that the vast majority of these studies used descriptive statistics and therefore cannot be extended to other student bodies.

There were some negative effects evident, two prominent ones were increased competitiveness between the students and a potential counter explanation that the positive effects may be due to a short term novelty factor [9].

Like Chatfield, Hamari also identifies a list of motivational factors which he names affordances. They are different then Chatfields, but there is definitely overlap.

1) Points

2) Leaderboards

3) Achievements/Badges

4) Levels

5) Story/Theme

6) Clear Goals

7) Feedback

8) Rewards

9) Progress

10) Challenge [9]

In a study that parallels the one to be discussed here in many ways, Denny found generally positive results in the gamification of the online community for a class of approximately 1000 students [10].

Though Chatfield, Hamari and Denny are all positive about the potential of gamification, Margaret Robertson and others would argue that the term has begun to be abused, particularly in business applications. Initiatives that only superficially address these motivational factors are being deemed as "innovative" gamification initiatives.

[T] hose who are trying to spice up their businesses with badges and levels don't actually understand how a game works. Rather than adding levels of engagement that make something fun, some of these applications simply add tracking systems..."pointsification" [11]

\section{GAMIFICATION OF A LARGE FIRST YEAR ENGINEERING DESIGN COURSE}

My goal with this study was to re-think, re-brand and reimplement an existing evaluation component of a first year design course to leverage some of these gamification motivational factors / affordances to subtly encourage more professional behaviour in the student body without 
a major resource investment. Pre-study $5 \%$ of the student grade was determined using a classroom response system. Initially we used iClickers [12], but recently moved to Top Hat [13] and cell phones. Students were given marks for each correct answer to in-lecture questions. Other than having to curb some cheating behaviour the systems worked well for their purpose, but I wanted to try to get more out them.

For this study, I first I increased the stakes to get students' attention, raising it from $5 \%$ to $10 \%$. Next I rebranded it. Rather than being called "iClicker grade" or "Top Hat grade" it was now in the syllabus as their "Professional Development grade." I kept the basic mechanic the same by saying that the Professional Development grade was based on the number of correct answers to in-lecture questions. For instance in the winter 2014 there were 42 in-lecture questions so a student who answered 30 of these correction would get 7.1 / 10 for their Professional Development grade.

The most significant change however came from the gamification of this grade. I identified a list of optional events which I felt contributed to the students' professional development. I then offered Bonus PD Points (see Table 1) for taking part in these events. Students who earned these bonus points could use them to "offset" any incorrect answers that may have lost them Professional Development grades. Bonus PD point events for both the Fall and Winter term include:

Table 1: Bonus PD Points for the Fall and Winter 201314

\begin{tabular}{|l|c|}
\hline Event & $\begin{array}{c}\text { Bonus PD } \\
\text { Points }\end{array}$ \\
\hline Workshop on Google Sketchup & +3 \\
\hline Optional oral presentation & +10 \\
\hline $\begin{array}{l}\text { Complete a personal leadership style } \\
\text { inventory }\end{array}$ & +10 \\
\hline $\begin{array}{l}\text { In-person ask an Engineering Librarian } \\
\text { a project-related research question }\end{array}$ & +2 \\
\hline Seminar on Intellectual Property & +2 \\
\hline $\begin{array}{l}\text { Online evaluations of members of the } \\
\text { teaching team }\end{array}$ & $+1 /$ \\
\hline $\begin{array}{l}\text { Hands-On Skills development workshop } \\
\text { run by a student design team. }\end{array}$ & +2 \\
\hline $\begin{array}{l}\text { Contributions to the online course } \\
\text { discussion forum (Top student } \\
\text { contributors; Top endorsed “good } \\
\text { questions”; Top Endorsed “Good } \\
\text { Answer”; Top 10 listeners) }\end{array}$ & +2 to +10 \\
\hline $\begin{array}{l}\text { Ministry of Labour - Worker Health and } \\
\text { Safety online training }\end{array}$ & +5 \\
\hline $\begin{array}{l}\text { Ontario Centre for Engineering and } \\
\text { Public Policy - Student Essay contest }\end{array}$ & +10 (+10 if \\
they won)
\end{tabular}

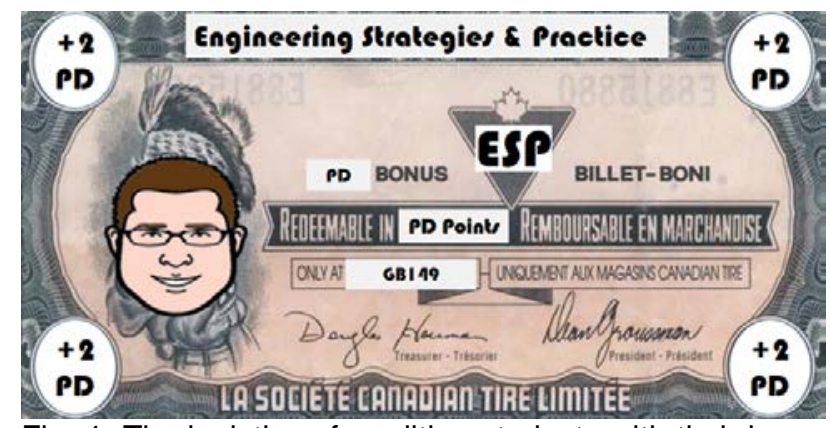

Fig. 1. The logistics of crediting students with their bonus PD points varied. For digital surveys the credit was recorded digitally by our Learning Management Software. For other activities such as visiting an engineering librarian we armed the librarians with this humorous cards modeled after Canadian Tire money. Students use the code on the back to claim their bonus points online.

\section{RESULTS}

The new gamified system definitely had an effect, mostly positive but with some negatives. The net effect was positive enough to warrant using a similar system next year, perhaps with some tweaks to address issues that will be discussed. The specifics of each gamified event are discussed below.

\section{Google Sketchup Workshop \\ +3 Bonus PD points}

This optional evening workshop was always popular with the students, but this year there was standing room only. Anecdotally there were more students this year, but no previous attendance data exists to confirm this.

\section{Engineering Librarian Visit +2 Bonus PD points}

In the previous year the engineering librarians couldn't remember more than a handful of students who actually came into the library and asked for help with their project research. This year we had 153 students (17\%) claim their PD bonus points earned by asking a project-related research questions of one of the librarians.

\section{Ontario Centre for Engineering and Public Policy Student Essay contest \\ +10 Bonus PD points (additional +10 if they won)}

14 students who entered this contest constitute only 1$2 \%$ of our student body, but I'm convinced we would have had zero entries otherwise.

\author{
Ministry of Labour - Worker Health \& Safety online \\ training \\ +5 Bonus PD points
}


The Ministry of Labour is driving to reduce work place accidents. One method is to better educate workers, particularly high risk workers, like our young, inexperienced students. 520 students (58\%) passed the online training found on the Ministry's website and earned their bonus points.

Intellectual Property Seminar by the Canadian Intellectual Property Office

+3 Bonus PD points

Intellectual property and patents is part of our course curriculum, but many students want more. We arrange an additional seminar for those students and managed to convince 166 students (19\%) to come out late one Friday afternoon.

\section{Hands-On Skills workshop} +3 Bonus PD points

Seven students $(<1 \%)$ attended a day long workshop run by SPARK, one of our student design teams, to enhance their basic hands-on build skills (power tools, soldering, etc).

\section{End-of-Term Survey \\ +1 Bonus PD point}

Each term we ask students to complete an optional end-of-term survey. This is in addition to the official course evaluations. We do this to collect more detailed feedback. In the Fall term we offered a lottery prize with a \$100 Amazon gift card being given to one person who completed the survey. With the previous system we got 209 responses (23\%). In the winter term we offered 1 bonus PD point for completing it and got 701 (79\%) responses.

Teaching Assistants (TA's) and Communication Instructor (CI's) Feedback

+1 Bonus PD point / evaluation

Each term we ask students to complete an optional survey to give feedback to their TA and CI. In the fall we offered no direct incentive and received a low response rate of 245 (27\%) for TA's and 175 (20\%) for CI's. This term we offered 1 bonus PD point for completing each survey. We received 737 responses (83\% response rate) for the TA evaluations and 721 responses (81\% response rate) for CI evaluations.

\section{Bolton Leadership Style Inventory \\ +10 Bonus PD points}

We instructed the students on the Bolton and Bolton leadership style inventory, but we wanted to have them complete the inventory and then report their style to us for use in team formation. 761 students (85\%) responded to our call in order to earn the bonus PD points.

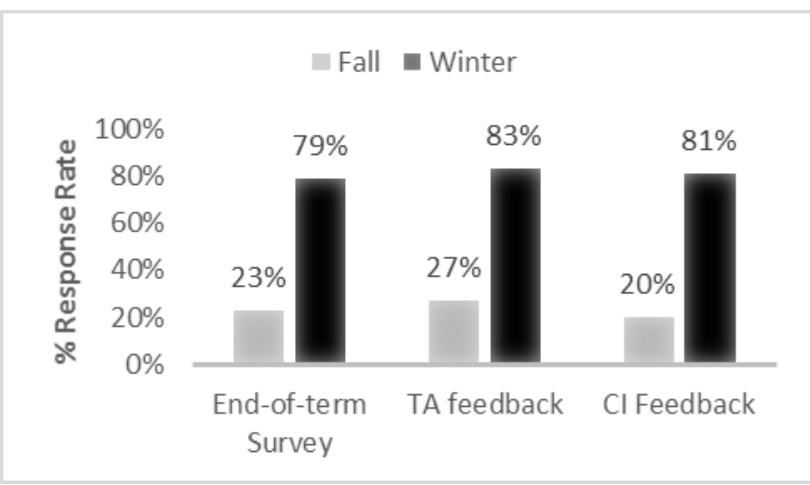

Fig. 2. In the fall we didn't offer any direct incentives for the TA and $\mathrm{Cl}$ feedback survey and offered a lottery for a single $\$ 100$ gift card for the End-of-Term survey. In the winter we offered 1 bonus PD point for each survey and yet saw a drastic increase in response rate.

\section{TED Talk Oral Presentation \\ +10 Bonus PD points}

Students were asked (optional) to find and watch a TED talk video presentation [14] and then present to their peers in tutorial on that video. 159 students (18\%) found time at a busy time of the year to practice their oral presentation skills.

\section{Online Discussion Forum}

+2 to +10 Bonus PD points

Piazza [16] is another new tool introduced this year that has been a huge success. In the fall term we had a total of 3022 contributions from an active student population of 808 (91\%). In the winter we saw a little drop off, but still respectable with 2705 unique contributions from an active 556 students (62\%). The only issue, from the perspective of this course, is that we are unsure if our success with our online forum stems from the new online forum tool itself or from our offering bonus PD points to leaders in the online community.

\section{DISCUSSION}

The power of the bonus PD points to motivate students to undertake tasks deemed by the teaching team to be beneficial was a runaway success. Quadrupling response rates in key information gathering tasks was beyond what we had hoped for, however after that initial glow wore off there were some issues we faced.

A major incident occurred with the optional Intellectual Property seminar. The seminar was scheduled primarily for an upper year course and so the timing was not ideal for a number of our first year students. This resulted in a large number of student complaints that it wasn't fair that the seminar conflicted with their lab or other mandatory activity. The general feeling from a significant number of the student body was 
that these were not "bonus points" and instead that they were entitled to them.

This sense of entitlement continued to the event when approximately 50 students who had arrived just as the seminar was completing were turned away from the door while I was still collecting attendance. The entitlement was so strong that students were extremely upset that they were being prevented from falsely claiming attendance at the event. This led to some additional unprofessional behaviour including cursing at a teaching team member.

We had underestimated the strong motivation these points had for the students, but also that students who wouldn't have cheated on an exam felt alright cheating for PD points. We speculate that part of this was due to the status of "points" buffering them from grades and so students felt more comfortable ignoring their ethical considerations. This meshes with Dan Ariely's study that showed people are more willing to cheat for tokens that can be converted into money than they are willing to cheat directly for money [15].

Another major limitation that has yet to be explored is the difference between quantity and quality. For instance with student feedback does the quadrupled number of responses actually net us more useful data. This is a question for a follow up study.

A decision I made in real time during an online help session was that students could get more than $100 \%$ on their PD grade. This simple decision may be responsible for some of the extreme results. Upon hearing this there was a significant number of students trying desperately to grab as many bonus PD points as possible regardless of any learning. The student at the optional Google Sketchup workshop who asked me, "what is this lecture about again?” falls in this category.

\section{REACTIONS}

Student responses have yet to be processed, but will be presented at the conference. Anecdotally the students neither loved nor hated the system, but did buy into it.

Members of the teaching team didn't have strong feels toward the system. Many did express concerns over their ability to improve as an instructor if they are getting little to no constructive student feedback. Though they have yet to see the actual feedback they were pleased to hear that the response rates are much higher.

\section{CONCLUSION}

In the goal to encourage students to participate in optional professional development activities we have succeeded with this implementation of a single gamified component. Minimal resources were spent, primarily administrative time to input the data into the grades management system, and yet we were able to drastically change student behaviour.

\section{FUTURE WORK}

The positive effect on student participation is too great to dismiss and so we will be implementing a similar system next year. We will tweak a few things to avoid issues. For instance we will try to eliminate as many avenues of cheating as possible. We will increase the number of Top Hat questions in order to dilute the value of the bonus PD points slightly. Finally we will better advertise the initiative to the students early in the term so that everyone has equal opportunity to participate.

\section{References}

[1] Wikipedia. (2014, Apr 17). The Oregon Trail (video game) [Online]. Available:

http://en.wikipedia.org/wiki/The Oregon Trail (video game)

[2] Wikipedia. (2014, Apr 17). Carmen Sandiego [Online]. Available: http://en.wikipedia.org/wiki/Carmen_Sandiego

[3] Bowman, R. F. (1982). A Pac-Man theory of motivation. Tactical implications for classroom instruction. Educational Technology, 22(9), 14-17. As reported in

Dixie. (2011, March 27). Reading for pleasure. Available: http://dixieching.wordpress.com/2011/03/27/a-pac-man-theoryof-motivation-bowman-1982/

[4] New Zoo. (2014). Global games market report infographics [Online]. Available:

http://www.newzoo.com/infographics/global-games-marketreport-infographics/

[5] International Federation of the Phonographic Industry. (2014, April). Global Statistics [Online]. Available: http://www.ifpi.org/global-statistics.php

[6] New Zoo. (2014). Infographic: The Canadian Games Market [Online]. Available: http://www.newzoo.com/infographics/infographic-the-canadiangames-market/

[7] Richard N. Landers. (2013, September 23). Media commons: A Digital scholarly network [Online]. Available: http://mediacommons.futureofthebook.org/question/how-doesgamification-affect-learning/response/many-faces-gamification [8] Tom Chatfield. (2010, July). "7 ways games reward the brain” [Online]. Available: http://www.ted.com/talks/tom chatfield 7 ways games rewar d the brain

[9] Juho Hamari, Jonna Koivisto, and Harri Sarsa, "Does gamification work? - A literature review of empirical studies on gamification," in Proc. 47th Hawaii International Conference on System Science, 2014. Doi: 10.1109.

[10] Paul Denny, "The Effect of Virtual Achievements on Student Engagement,” in Proc. Computer Human Interaction, 2013. 
Proc. 2014 Canadian Engineering Education Association (CEEA14) Conf.

[11] Margaret Robertson. (2010, October 6). "Can't Play, Won't Play," Hide\&Seek, Available: http://hideandseek.net/2010/10/06/cant-play-wont-play/

[12] iClicker. (2014). Top student response and audience response system [Online]. Available: http://www1.iclicker.com [13] Top Hat. (2014). Bring your lectures into the $21^{\text {st }}$ century [Online]. Available: https://tophat.com
[14] Technology Entertainment and Design. (n.d.). Ideas worth spreading [Online]. Available: http://www.ted.com

[15] Dan Ariely. (2009, February). "On our buggy moral code” [Online]. Available: http://www.ted.com/talks/dan ariely on our buggy moral cod $\underline{\mathrm{e}}$

[16] Piazza. (2013). Piazza. Ask. Answer. Explore. Whenever. [Online].
Available: https://piazza.com 